\title{
APFELSTRUDEL, 80 CAMADAS DA MAIS FINA MASSA FOLHEADA DE MÚLTIPLOS EUS: UMA HOMENAGEM A CLAUDIO WILLER
}

\author{
Marta Dantas ${ }^{*}$ \\ Vanessa Tavares da Silva*
}

RESUMO: O presente ensaio é uma homenagem ao poeta, ensaísta e tradutor paulistano Claudio Willer que, em dezembro de 2020, completou 80 anos. Por meio de um diálogo entre seus textos em prosa, alguns poemas e sua fortuna crítica, far-se-á um exame de sua trajetória, iniciada em meados da década de 1960. De matriz surrealista, sua atuação se dá, sobretudo, numa atitude que entrelaça sua produção com um modo de vida que, por sua vez, se desdobra nessa produção. O poeta absorve, em sua prática, uma concepção da literatura livre do cerceamento da razão e aberto à contemplação do caráter enigmático e mágico do universo. Nessa perspectiva, traduziu obras de autores importantes para os fundamentos do Surrealismo e da literatura beat. Partindo das considerações de Leila Perrone-Moisés, é possível compreender as múltiplas atuações de Willer, seu jogo profuso de Eus, poeta, tradutor e crítico teórico, com os mais diversos interlocutores, como componentes de um escopo necessário à vitalidade dos pressupostos surrealistas na atividade artística e literária do país. O entrecruzamento de suas ações sinaliza também a própria tessitura da intertextualidade de sua poesia, seu recurso mais radical. Afinal, antiaristotélico pelo avesso, a palavra poética é, para Willer, agente mágico que produz realidade.

PALAVRAS-CHAVE: Claudio Willer; Poesia; Surrealismo no Brasil; Trajetória poética/teórico crítica

\section{Puccini, Willer e eu: estranhas experiências ${ }^{1}$}

Depois de cumprir as tarefas diárias, corri em direção aos seus brinquedos prediletos: Dias ácidos, noites lisérgicas (WILLER, 2019). Meus olhos deslizavam sobre as palavras. Era como uma viagem no tempo que fazia com que o presente, o passado e o futuro se encontrassem em alguns pontos.

Passei pelas ruas de São Paulo, pelo litoral do Guarujá. A errância do narrador nos anos 60 lançava luz sobre a minha, quando eu era adolescente, nos anos 80. Lembrei que a primeira vez que assisti a um filme do Buñuel foi na Livraria Belas Artes, na Avenida Paulista,

\footnotetext{
* Doutora em Sociologia pela Universidade Estadual Paulista Julio de Mesquita (Unesp). Professora associada C da Universidade Estadual de Londrina (Uel). Fez estágio pós-doutoral em Literatura Brasileira na Universidade de São Paulo (Usp). Autora do livro Arthur Bispo do Rosário: a poética do delírio. São Paulo: Ed. UNESP, 2009.

** Doutoranda em Letras pela Universidade de Londrina (Uel). Mestre em Cultura Visual pela Faculdade de Artes Visuais da Universidade Federal de Goiás (UFG). Professora do Departamento de Arte Visual da Universidade Estadual de Londrina (Uel).

${ }^{1}$ A primeira parte deste ensaio, Puccini, Willer e eu: estranhas experiências, é o resultado parcial de uma Oficina de Criação Literária ministrada por Claudio Willer em 2020, o que justifica estar escrito em primeira pessoa e o seu tom mais poético.
} 
uma livraria muito pequena e estreita e que tinha uma escada que dava acesso a uma salinha ainda menor no piso superior, com poucas cadeiras e uma ou duas mesinhas rodeadas de caixas de livros e uma televisão que abriu os meus olhos para Esse obscuro objeto do desejo. Era 1984, eu não podia imaginar que, anos mais tarde, o Surrealismo se revelaria como objeto do meu desejo.

A Livraria Belas Artes foi um dos redutos da cultura paulistana. Nela, sem que eu mesma soubesse, talvez tenha começado o meu processo iniciático (e imagino, que o de tantas outras pessoas). Lamentavelmente suas portas de fecharam em 2006 e desde então sobrevive na memória das várias gerações que passaram por lá. Mas as minhas andanças e experiências pela capital paulista pouco têm a ver com aquelas do narrador. Aliás, ele é de São Paulo e eu pertencia a outros santos.

Volto ao livro, na página 109. Detenho-me na frase: “Achava estranho Breton haver abandonado, em uma certa altura, a categoria 'acaso objetivo', encontro do desejo e da necessidade, depois de escrever tanto a respeito em O amor louco e outras de suas obras" (WIILER, 2019, p. 109). Rapidamente grifo à lápis e escrevo ao lado: CONCORDO!! Como poderia Breton abandonar essa categoria de evento que me fez amar Nadja e reencantou a minha vida e de tantas outras pessoas? E logo em seguida vem um grande consolo: "Henry Béhar [...] esclarece [...]. Substituiu. Em vez de acaso objetivo [...] passou a referir-se a 'magia', pura e simplesmente" (WIILER, 2019, p. 109). Ufa! Magia, magia!

Retorno à leitura. Uma nova interrupção causada pelas minhas gargalhadas: "A realidade parecida com a massa folheada cobrindo o recheio de um Apfelstrudel, com finas camadas?” (WIILER, 2019, p. 111). Noite lisérgica? Nem tanto. Divaguei sobre acaso objetivo. “Quem já não passou por isso? Lembrar-se de alguém e em seguida a pessoa telefonar ou cruzar o seu caminho?” (WIILER, 2019, p. 111). De fato, quem já não passou por isso? "É como se fossemos máquinas loucas, receptores aleatórios, equipamentos pegando o que estiver no ar, sem critérios ou processo de seleção" (WIILER, 2019, p. 111). E o narrador prossegue: "Explicações, não tenho. O tempo com muitas dimensões? [...] O eu múltiplo?”. E aí vinha o que motivou minha sequência de gargalhadas, "[...] a realidade como uma massa folheada" (WIILER, 2019, p. 111). Imaginada assim, a realidade se torna mais apetitosa: a crocância das várias camadas de massa levemente salgada, o sabor delicado e adocicado do creme; o ponto de encontro entre os opostos: o doce e o salgado, a aspereza e secura da massa com o aveludado cremoso. Essa imagem não saiu mais da minha cabeça.

O narrador contava, entre outras coisas, sobre seu gosto pela música erudita, mais precisamente pela ópera, e como ela o aproximou de um sujeito que terminou se tornando 
seu amigo: “[...] vi um tipo, enorme, nadando com largas braçadas na piscina [...] e ao mesmo tempo cantando uma ária de ópera a plenos pulmões, 'Ch'ella mi creda libero e lontano' de La Fanciulla del West de Puccini, fui falar com ele, ficamos amigos" (WILLER, 2019, p. 117). Mais uma vez interrompi a leitura para refletir sobre a erudição, sobre a educação do meu narrador. O que será que há de especial na ópera? Acabava de descobri que a tal ópera, La Fanciulla del West, mudou a opinião de Michel Leiris sobre Puccini e que Turandot, apreciada pelo narrador, foi escrita enquanto o compositor era consumido pelo câncer na garganta. Enquanto pensava sobre a importância da ópera para o narrador, meus olhos se voltaram para a tela da televisão. Acredite se quiser, naquele instante, o canal Arte 1 transmitia um programa sobre ópera, mais especificamente, sobre Puccini. Rapidamente aumentei o volume e ouvi o apresentador do programa comentar sobre La Fanciulla del West e, na sequência, sobre o câncer na garganta do compositor. Eu precisava de uma testemunha! Mostrei a página 117 do livro onde se encontra a passagem que acabei de reproduzir. Acaso objetivo! Magia! "Explicações, não tenho. O tempo com muitas dimensões? [...] O eu múltiplo?” (WIILER, 2019, p. 111). Continuei a leitura até o sono me vencer.

\section{Quem é Claudio Willer?}

como poeta, o ambiente no qual circulo é o surrealismo

Claudio Willer

No seu poema "Autobiografia selvagem", o eu lírico diz a que veio o poeta:

1964: A grande risada. Contemplei o mundo, presenciei os fatos de perto, a partir da minha cama. Impossíveis outras posturas. Alucinações no Maranhão e Recife. Que odor de ferrugem permeava as madrugadas! Mas algo se preparava. ${ }^{2}$ (WILLER, 2004a, p. 76)

$\mathrm{Na}$ porta de seu quarto, poderíamos ler o aviso: “O POETA ESTÁ TRABALHANDO” (BRETON, 2001, p. 28). 1964 foi o ano em que preparou e se lançou com Anotacões para um Apocalipse, seu primeiro livro de poesias. O odor de ferrugem que permeava as madrugadas eram odores! E tinham nome:

fernandopessoapierrereverdysaintjohnperserobertdesnosviniciusgisnbeg

corsoferlinghettibretonpauléluardmallarméartaudrilkerousselponge poundcarlosdrummondoswaldmariomichauxlautréamontnerudanovalis blakebenjaminpéretkleisthöerdelinnietzschesenghorcézaireoctaviopaz

\footnotetext{
${ }^{2}$ Respeitamos o formato original dos poemas.
} 
pivamachadoalbertcernudajarryeliotstephangeorgerimbaudcummings cabraltzaracrevelmuriloapollinairesoupaulttralklbennbaudelaire

(WILLER, 2004a, p. 65)

Era o Apocalipse que se preparava; e numa inversão do tempo linear do cristianismo, ele foi o princípio, resultado de leituras, viagens, encontros e um estilo de vida que Willer mantém, que se transforma e que retorna, de volta, novo, ao ponto de partida, à origem, ou seja, à magia das palavras. Afinal, o "[...] fato de que a atuação da palavra vai muito além de todo 'entendimento', é algo que não precisa apoiar-se na especulação religiosa, pois tal é a experiência do poeta, do místico e de todo [...] falante que se delicia com e elemento sensível da palavra" (SCHOLEM, 1999, p. 15).

Claudio Jorge Willer nasceu em São Paulo em 1940. Filho de um casal europeu e poliglota, Willer aprendeu várias línguas. Seu interesse pela literatura surgiu cedo: aos quinze anos já era leitor de Dostoiévski e o encontro com a poesia se deu assim que seus passos deixaram de ser restritos ao círculo familiar e ganharam as ruas da cidade. Graduou-se em Sociologia, em 1963, pela Escola de Sociologia e Política de São Paulo e, em 1966, em Psicologia pela USP. Doutorou-se em Letras pela USP, em 2008, com a tese Um obscuro encanto: gnose, gnosticismo e a poesia moderna, publicada pela Civilização Brasileira (2010) e, na mesma instituição, concluiu em 2011 seu pós-doutorado com ensaios sobre o tema Religiões estranhas, misticismo e poesia.

Willer, na introdução de sua tese, assinala as matrizes do que foi e do que tem sido sua atuação desde o início de sua trajetória:

Talvez desde a leitura, na década de 1960, de O Arco e a Lira de Octavio Paz, com o capítulo em que há paralelos entre o poeta e o mago. Logo a seguir, empreendi a leitura do Dogma e Ritual de Alta Magia de Éliphas Lévi e outras de suas obras, bem como de Papus e mais alguns especialistas nesse campo. Antes, já havia lido bastante Breton, inclusive as passagens sobre alquimia, astrologia e esoterismo do Segundo Manifesto do Surrealismo. Reflexos dessas leituras são evidentes em meus poemas então publicados. O mesmo interesse determinou que tivesse nas mãos, logo após sua publicação, Los Hijos del Limo, o ensaio de Octavio Paz que continua O Arco e a Lira e retoma o exame do pensamento analógico e sua relação com ocultismo. Atraiu-me também a noção bretoniana de acaso objetivo: a projeção do desejo, estabelecendo relações mágicas entre o mundo simbólico e aquele dos fenômenos. Tais relações foram o tema de minha narrativa em prosa de 1996, Volta. (WILLER, 2008, p. i)

Em História da Literatura Brasileira, de Carlos Nejar (2011), Willer se encontra no capítulo dedicado à "Poesia brasileira da Geração de 1960 até 1970" e é o único autor sob a rubrica "O Surrealismo". Nos seus poemas, explica Nejar (2011), encontramos imagens insólitas:

"O grande cavalo de lágrimas azuis desce do Oeste, lento como a névoa dos trigais” [...] Ou o dilúvio e atropelamento no catalogar caótico de metáforas 
("silêncio de cascos estilhaçados de tartaruga"), em que a lógica não importa, mas a velocidade dos sonhos e "a queimadura do fósforo da poesia consumindo-se". (WILLER apud NEJAR, 2001, p. 991)

Outras vezes, seu poema é “[...] um raio de lucidez atordoante” (NEJAR, 2011, p. 992):

"uma geração pulou no abismo/ mas você foi mais adiante/ ou saltou mais fundo/ levantou a tampa da vida/ para ver o que havia por baixo/ para ver que não havia nada embaixo". (WILLER apud NEJAR, 2011, p. 992)

Seus poemas, observa Alves-Bezerra (2016, p. 48), "anotam visões ou as suscitam no leitor”; eles são visionários, afinal, “[...] na poesia o futuro é revelado” (WILLER, 2004a, p. 87).

Suas publicações são muitas e em vários gêneros. Poesia: Anotações para um Apocalipse (Massao Ohno Editor,1964), Dias circulares (Massao Ohno Editor, 1976), Jardins da provocação (Massao Ohno/Roswitha Kempf Editores, 1981), Estranhas experiências - poesia 1964-2004 (Lamparina, 2004), A verdadeira história do século 20 (Córrego, 2016). Prosa: Volta (Iluminuras, 2004), Dias ácidos, noites lisérgicas (Córrego, 2019). Ensaios: Geração Beat (L\&PM Pocket, 2009), Um obscuro encanto: gnose, gnosticismo e a poesia moderna (Civilização Brasileira, 2010), Manifestos 1964-2010 (Azougue, 2013), Os rebeldes: Geração Beat e anarquismo mistico, ensaio (L\&PM, 2014).

Poeta e ensaísta ligado à criação literária rebelde, ao Surrealismo e à geração beat é também tradutor excepcional de autores como: Conde de Lautrémanont, Antonin Artaud, Allen Ginsberg, Jack Kerouac, Charles Bukowsky e Aimé Césaire. Willer está presente no Dictionnaire général du Surréalisme et de ses environs (1985). E ainda há quem diga que não houve e não há Surrealismo nos trópicos.

Em uma trajetória de anos dedicados à pesquisa e à divulgação de tradições literárias transgressivas, conta com mais de quarenta de publicações em antologias e periódicos no Brasil, Argentina, Colômbia, Alemanha, México, Venezuela, Costa Rica e na Itália. Atuou como crítico e ensaísta no Jornal da Tarde, Jornal do Brasil, Folha de São Paulo, como também, nas revistas Cult e Isto É, entre outros meios impressos.

Foi Presidente da União Brasileira de Escritores nos períodos de 1988-1992 e 20002004 e trabalhou na Secretaria Municipal de Cultura de São Paulo como coordenador da Formação Cultural entre 1994-2001. Como administrador cultural em cargo público, foi responsável por um trabalho de registro histórico, de divulgação de poesia e por iniciativas de difusão social da literatura por meio da organização de eventos culturais. Em sua atuação, na qual é perceptível a desenvoltura com o aparelho cultural, Willer provocou a divulgação e a criação de um circuito de recepção. A agitação cultural provocada por ele não se restringe aos espaços oficiais de cultura, se estende também ao meio underground paulistano e faz parte 
da história cultural paulistana. Em 1983, por exemplo, participou da cerimônia de inauguração da casa noturna que marcou toda uma geração paulistana, Madame Satã, com a leitura performática de poemas de Pierre Riverdy, Octavio Paz e fragmentos de Uivo, de Allen Ginsberg. Atua, ainda hoje, de modo peculiar, fora do âmbito acadêmico, ministrando inúmeros cursos, palestras e coordenando oficinas em diversas instituições culturais. Tem uma intensa produção textual em mídias diversas. Participa de bancas, ministra palestras e cursos em instituições de ensino superior, pois é uma referência nos estudos relativos ao Surrealismo e a Geração Beat.

\section{Os entrecruzamentos como fonte para a análise teórica e crítica}

A crítica literária, desde seu surgimento, passou por transformações significativas relativas aos seus métodos e mesmo à sua perspectiva, muitas delas devidas às transformações pelas quais a arte, a literatura, enfim, o contexto sociocultural e o homem passaram. Nesta breve homenagem, far-se-á um exame dessa situação no Brasil, pontualmente, na produção do poeta, ensaísta e tradutor Claudio Willer, que começou atuar em meados da década de 1960.

Leyla Perrone-Moisés, em Altas literaturas (1998), apresenta o percurso da crítica literária para traçar um perfil, no século $\mathrm{XX}$, de um crítico cujas atividades, para além daquelas estritas ao seu campo, o situa em um patamar distinto:

\footnotetext{
Desde sua prática autoritária no século XVII, sob a forma de decretos da Academia, passando pelas escolhas já pessoais dos críticos do século XVIII, até o fim do século XIX, quando ela atingiu a plenitude de seus meios e de seu poder como instituição autônoma, a crítica literária reivindicou e exerceu a função de julgar. [...] Ao longo do século XX, essa certeza foi sendo abalada. [...] No vocabulário crítico do nosso século, os adjetivos qualificativos se tornaram raros e discretos [...]. (PERRONE-MOISÉS, 1998, p. 9)
}

Diante desse panorama, Perrone-Moisés reconhece que, por mais que não estejam explícitas as regras de julgamento, a própria escolha de determinada obra já se coloca como um ato que a qualifica. Nesse sentido, encaminha seu estudo para o que, até então, não havia sido feito de modo sistemático: o exame, no século $\mathrm{XX}$, da crítica literária exercida pelos próprios escritores e salienta: "O fato de que numerosos escritores de nosso século tenham acrescentado, à sua obra poética ou ficcional, uma obra paralela de tipo teórico e crítico tem a ver com o mal-estar da avaliação.” (PERRONE-MOISÉS, 1998, p. 11). 
Flora Süssekind, no texto Rodapés, tratados e ensaios - a formação da crítica brasileira moderna (1993), faz o exame das práticas vigentes, assim como de suas transformações nos meados dos anos de 1940 até 1980. Nessa passagem de tempo, em meio às transformações pelas quais passou o circuito da produção literária e o exercício da crítica no Brasil, destaca o surgimento do crítico teórico. A autora recupera o período em que figura a intensidade da crítica não especializada em confronto com o surgimento da crítica especializada. O que foi a prática do final do século XIX e início do século XX, a chamada crítica impressionista, exercida no espaço dos rodapés dos jornais, passou a ganhar novos contornos com "[...] as primeiras gerações de formandos das faculdades de Filosofia criadas nos anos 30" (SÜSSEKIND, 1993, p. 13), quando o espaço da crítica passou da resenha de jornal para o livro.

No âmbito da passagem da crítica não especializada para a especializada, Süssekind evidencia os embates nos quais se discutiam " [...] as normas que passam a regular o exercício do comentário literário e a qualificar ou desqualificar os que se dedicavam a ele, agora segundo critérios de 'competência' e 'especialização' originários da universidade" (SÜSSEKIND, 1993, p. 18). Destaca ainda as divergências dentro da própria crítica especializada, dadas as diferenças de concepções, o decreto que regulamenta a profissão de jornalista, do final da década de 1960, e as demandas do mercado editorial, na década de 1980, como fatores que deram contorno aos embates e geraram o crítico teórico como mais uma modalidade no exercício da crítica. Ele se situaria na:

Terceira margem da disputa, porque, de certa forma, 'antagonista', nos dois espaços em questão, caberia talvez ao crítico teórico o papel de multiplicar dissenções e fortalecer um contradiscurso duplamente orientado que, de fora do duelo, jogasse por terra suas regras. (SÜSSEKIND, 1993, p. 32)

Essas transformações nos auxiliam no exame da atuação de Claudio Willer, compreendendo-a também como a de um crítico teórico, cuja trajetória tem certas nuances e peculiaridades, tanto a partir do contexto no qual sua atuação começou quanto à natureza de sua produção como poeta e articulador do meio.

A intensidade de suas atividades se deu, inicialmente, como poeta. $\mathrm{Na}$ dissertação intitulada Estilhaços de visões: poesia e poética em Roberto Piva e Claudio Willer (2012), Fabrício Carlos Clemente aponta o início de sua trajetória:

O marco de referência da produção dos poetas contemporâneos brasileiros Roberto Piva e Claudio Willer encontra-se na leva de autores apresentados ao público da São Paulo dos anos sessenta pelo importante trabalho do editor Massao Ohno. A antologia dos Novíssimos (1961), juntamente com a coleção homônima, mais os projetos de títulos inequívocos tais como a "coleção Maldoror" tiraram do ineditismo muitos dos jovens escritores que então surgiam no cenário paulistano. (CLEMENTE, 2012, p. 8) 
A poesia de Claudio Willer, assim como a de Antonio Fernando de Franceschi (1942) e a de Roberto Piva (1937-2010), faz parte da cena literária paulistana do início dos anos 1960. Vieram a público com a Antologia dos novíssimos (1961), publicada por Massao Ohno. Apresenta-se uma nova geração, mas não um grupo homogêneo de poetas, pois, explica José Mariano Carneiro da Cunha na breve apresentação que faz da antologia, eram “" [...] jovens das mais variadas tendências, pontos de encontro dos diversificados contrastes que nos delinearam o modo de ser brasileiro"' (CUNHA, 1961, p. 5 apud LYRA, 1995, p. 133). O que unia e definia a geração dos novíssimos era a rebeldia:

[...] jovens poetas, rebelados sem uma motivação específica, porque tudo são indagações para os inconformados. Revolucionário? Sim [...] Revolucionários porque acreditam no poder instaurador da poesia e estão certos de que "só poeticamente se pode viver" [...]. (CUNHA, 1961, p. 6 apud LYRA, 1995, p. 133, 134)

Tal geração vivia a efervescência de um momento específico no país e, segundo Willer, eles tinham “[...] abertura, esse cosmopolitismo de nos interessar pelo que acontecia no mundo todo e, evidentemente, por manifestações com uma dimensão crítica, que significassem algum tipo de ruptura ou subversão". (WILLER, apud CLEMENTE, 2012, p. 12).

Do ponto de vista da cena literária, tínhamos na época a atuação do grupo que se formou a partir da revista, fundada em 1952, Noigandres. Sua formação contava com os irmãos Haroldo e Augusto de Campos e Décio Pignatari. Tratava-se de um movimento de vanguarda que se opunha ao que vinha sendo desenvolvido pela geração de 1945. Eles postularam os princípios da poesia concreta:

[...] palavras sôltas e muito maior preocupação com a imagem visual, com o pictórico
do que com o conceito, numa clara resposta às solicitações da civilização industrial-
eletrônica, da sociedade da rapidez, concisão e objetividade. Amparada por uma pro-
fusa teoria [...] a poesia dêsse jovem grupo paulista passa "do verso para a poesia
concreta". (COELHO, 1971, p. 20 )

No âmbito, tanto da produção quanto da teoria, o Concretismo, surgido em 1956, propunha: o abandono do eu lírico; a linguagem direta e econômica da poesia "pau-brasil" de Oswald de Andrade - “[...] em comprimidos, minutos de poesia” (ANDRADE, 1974, p.70) - e João Cabral de Melo Neto; o uso do espaço e dos recursos tipográficos tal qual Mallarmé em Un coup de dés jamais n'abolira le hasard de1897; a atomização de palavras; a palavra ideograma; a comunicação "verbivocovisual". Segundo o "plano-piloto para poesia concreta", de 1958:

[...] poesia concreta: produto de uma evolução crítica das formas. [...], o poema concreto comunica a sua própria estrutura: estrutura-conteúdo, o poema concreto é um objeto em e por si mesmo, não um intérprete de objetos exteriores e/ou sensações mais ou menos subjetivas. seu material a palavra (som, forma visual, 
carga semântica). seu problema funções-relações desse material [...] cronomicrometragem do acaso. controle. [...] a comunicação mais rápida [...]. realismo total. contra uma poesia de expressão, subjetiva e hedonística. [...] o poema-produto: objeto útil. (CAMPOS; PIGNATARI; CAMPOS, 1977, p. 78-79)

Os novíssimos configuravam-se também como vanguardistas, só que na contramão do grupo concretista. $\mathrm{O}$ abandono do eu lírico - uma das premissas dos poetas concretistas - implicava um grave problema, já que esse era o mote de suas produções. O que estava em xeque era a tomada de consciência crítica do sujeito frente às condições dadas pelo projeto moderno civilizatório, calcado no racionalismo, e evidenciar o Eu cindido, compreendido à luz de suas experiências com a cidade:

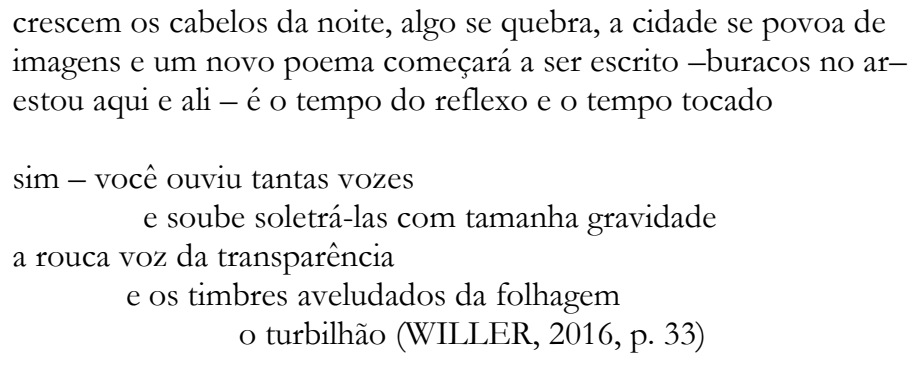

Novíssimos e concretistas valorizavam a geração de 1922 sob pontos de vista distintos. Segundo Willer, “[...] ler Mário era duplicar a vivência de São Paulo, frequentando também no plano do texto os lugares por onde se transitava no cotidiano, assimilando sua visão poética do espaço urbano" (WILLER, 2000, p. 229, apud CLEMENTE, 2012, p. 13). A esse respeito, Clemente retoma a consideração de Willer (2000) acerca do grupo quando diz que, embora não seja possível falar em atitude unânime em relação aos modernistas de 22, é inegável que suas percepções sobre São Paulo constituem importante elemento para alguns dos novíssimos, como Carlos Felipe Moisés e Roberto Piva (CLEMENTE, 2012, p. 13). Ainda quanto às diferenças entre os novíssimos e o grupo da poesia concreta, evidenciando o modo como lidavam com a situação da produção literária, vale ressaltar as palavras de Willer numa matéria publicada em 2004 na revista Cult ed. $76^{3}$ :

A relação com os de 45, que dominavam o panorama cultural, era ambivalente. Houve quem fosse adotado como sucessor. E quem a combatesse. Poesia concreta, sim, era unanimidade negativa. Para muitos, em nome da permanência do verso. Por serem engravatados, bem-comportados. Por entenderem que, com as novas tecnologias, informática etc., viria uma nova linguagem, em forma de ideograma. Décio Pignatari deixou crescer a barba e o cabelo; mas, na crítica ao cientificismo, ao culto à tecnologia, tínhamos razão [...]. (WILLER, 2004, s/p)

\footnotetext{
${ }^{3} \mathrm{Na}$ edição impressa da revista, o texto fazia parte da seção Dossiê, sob o título: Um passeio pela vanguarda de São Paulo nos 450 anos da cidade. O mesmo texto consta numa versão eletrônica da revista, sob o título: Dias Circulares, conforme mencionado nas referências.
} 
Estranhas experiências, o onirismo, a mística, o mito, o pensamento analógico, o indizível, o inexprimível, uma imbricação entre Surrealismo e Beat, ou, como prefere Duarte Neto, um "Surrealismo Beat", é o que esteve e está na ordem do dia para o novíssimo Willer, que sempre se nutriu do contato com a produção poética e teórica de autores trágicos, românticos e/ou críticos do racionalismo:

Pode-se depreender das referências mencionadas por Willer tópicos significativos com a preocupação metafísica (Rilke), o interesse pelo sentido e poder dos mitos (Eliade), a visão fragmentada e crítica da modernidade (Eliot), a angústia cósmica do sujeito moderno (Saint John Perce), a procura pela essência da linguagem e da arte concernente ao sentido do ser (Heidegger), o ímpeto encantatório e rebelde frente à realidade utilitária do mundo burguês - marcada, neste caso específico, pelo acento trágico da loucura (Hölderlin, Artaud, Van Gogh); e ainda, o interesse por outras culturas, cosmogonias, e formas de pensamento com ênfase no orientalismo e no paganismo. (CLEMENTE, 2012, p. 18)

Isso porque, para Willer, a poesia almeja um outro mundo neste mundo, ou o outro lado deste mundo, “[...] quando nenhum poema automático for bloqueado e nenhum/ sonho deixar de ocupar seu lugar" (WILLER, 2016, p. 32):

\author{
O OUTRO LADO \\ só assim o poema se constrói: \\ quando o desejo tem forma de ilha \\ e todos os planetas são luas, embriões da magia \\ então podemos atravessar as chamas \\ sentir o chão respirar \\ ver a dança da claridade \\ ouvir as vozes das cores \\ fruir a liberdade animal \\ de estarmos soltos no espaço \\ ter parte com pedra e vento \\ seguir os rastros do infinito \\ entender o que sussurra o vazio \\ - e tudo isso é tão familiar \\ para quem conhece \\ a forma do sonho (WILLER, 2004a, p. 46)
}

A valorização deste outro lado não significa ignorar as relações entre arte e sociedade. Para Floriano Martins (2013, p. 190), “[...] nenhum outro poeta no Brasil tomou para si a tarefa de considerar como indissociáveis as relações entre poesia e sociedade." Essas relações não são óbvias. Em sua obra inaugural, Anotações para um apocalipse:

[...] o apocalipse aludido pode ser visto como uma ressignificação do ideário místico cristão [...]. Mas também pode ser a antevisão do funesto golpe militar do ano de publicação do livro, 1964 [...] Todavia, e é em parte a própria interpretação que o poeta deixa implícita em um dos seus manifestos, a apocalipse seria a profecia de uma espécie de fim dos "velhos" tempos. (DUARTE NETO, 2018, p. 31) 
A década de 60 do século passado foi constituída de uma série de eventos e conquistas importantes; fato é que Anotações para um apocalipse não é nem reflexo e nem uma representação de nenhum deles, mas a gestação, como explica Duarte Neto (2018, p.38), de todos eles. Afinal, nos lembra Octavio Paz:

[...] não há poesia sem sociedade, mas a maneira de ser social da poesia é contraditória: simultaneamente afirma e nega a fala, que é palavra social; não há sociedade sem poesia, mas a sociedade não pode se realizar nunca como poesia, nunca é poética. [...]. Condenados a uma conjunção perpétua que desemboca em instantânea discórdia, os dois termos buscam uma conversação mútua: poetizar a vida social, socializar a palavra poética. Transformação da sociedade em comunidade criadora, em poema vivo; e do poema em vida social, em imagem encarnada. (PAZ, 2012, p. 259-260)

Afinal, antiaristotélico pelo avesso, a palavra poética é, para Willer, agente mágico que produz realidade.

Em 1964, aos vinte e quatro anos, Willer publicou seu primeiro livro de poesia, Anotações para um apocalipse. Alguns anos depois, em 1970, lançou a tradução dos Cantos de Maldoror ${ }^{4}$, de Lautréamont. Em 1984, Willer traduziu Allen Guinsburg ${ }^{5}$, autor beat, com quem trocou correspondências. Em entrevista, Willer contou ${ }^{6}$ que seu trabalho como tradutor foi obra do acaso objetivo ${ }^{7}$, de propostas inesperadas de editores, nada premeditado: "Fui um afortunado", afirmou o poeta. O entrecruzamento entre o trabalho de criação poética e o de tradutor, entre o poeta e o ensaísta, sinaliza a própria tessitura da intertextualidade de sua poesia

A atitude de Willer junto aos novíssimos não tinha, precisamente, um lugar. É compreensível, desse ponto de vista, a atitude de invenção desse lugar na ação que empreendeu no contexto da cidade de São Paulo, que, na época, já passava a ter alguns traços da agitação cultural de hoje. Sua relação com Piva, Franceschi e outros novíssimos não poderia ser melhor expressa do que em seu poema dedicado aos seus amigos:

\footnotetext{
${ }^{4}$ Sua primeira versão d'Os Cantos de Maldoror, de Lautréamont é de 1970, publicada pela editora Vertente, e conta com ilustrações da artista plástica surrealista Maninha Cavalcante; a segunda versão, de 1986, foi publicada pela editora Max Limonad e a terceira, de 2018, acrescida de um ensaio do tradutor e de poesias e cartas de Lautréamont, foi publicada pela editora Iluminuras.

${ }^{5}$ Desde os primeiros anos da década de 1960 Willer foi um leitor voraz de Guinsburg, uma referência constante na sua formação.

${ }^{6}$ Declaração do autor em live na Confraria da Palavra, no dia 24 de abril de 2021: https:/ / meet.google.com/ pibhbbx-etm

${ }^{7}$ Segundo André Breton: "O acaso seria a forma de manifestação da necessidade exterior que abre caminho no inconsciente humano" (apud CHÉNIEUX-GENDRON, 1992, p. 92). Trata-se de um encontro excepcional entre a necessidade natural e a necessidade humana, em outras palavras, do encontro entre o desejo inconsciente do homem e a possibilidade de sua realização. O acaso é chamado de objetivo porque se refere à realização, objetiva, de uma subjetividade desejante.
} 


\section{OS POETAS PAULISTAS}

o poema,

só quando for impossível traduzir um estado interior de outro modo

só quando for preciso dizer algo inexprimível, como o cheiro de café expresso que tomava conta da Praça Roosevelt a provocar um retorno a invernos de outras cidades

e para transmitir como foi aquela encenação da Teogonia, do poema

sobre os mitos arcaicos, a vida e a morte, o fim e o recomeço como etapas do mesmo ciclo luminoso

pois a Terra, aquela noite, era um bólido que atravessava acelerado o universo e uma torrente de chuva

as gotas da noite na partitura dos minutos estampada no para-brisa uma tempestade nos encerra no centro do planeta que tem a forma de uma garagem subterrânea

e os poemas são escritos assim, de madrugada

para dizer que nossos dentes são sensuais, nossas mãos são tão leves nossos corpos se tocam o vazio é perfeito e o mar está em nós

- agora devo habituar-me a inesperadas proporções e novas simetrias de estarmos juntos, pois nós nos tornamos a extensão de um texto de frases entrecortadas sobre o alvor fugidio, esse clarão que nos separa do [amanhecer de um dia seguinte quando o cheiro de outro corpo, o seu, me acompanhar e vier acrescentar-se à minha biografia (WILLER, 2016, p. 30)

A autorreferência neste poema, "[...] transforma o poeta em personagem coadjuvante da própria poesia, de seu próprio século, conferindo centralidade mais às visões do que àquele que as produz" (ALVES-BEZERRA, 2016, p. 48). O poema traz à tona a amizade, sobretudo entre Willer e Roberto Piva, marcada pela troca de livros, de ideias, de referências, de telefonemas, pela imbricação das palavras de um na frase do outro, criação poética que implica no texto outro, no outro do texto, experiência de "outridade", no dizer de Paz (2012), ou seja, em estados de solidão e comunhão com o outro que, de modos diversos, nos habita; e também na experiência de apropriação no processo de criação, expresso por Lautréamont na sua máxima "A poesia deve ser feita por todos, não por um".

\section{Revisão e lugar}

Cada vez mais livres, através dos séculos XIX e sobretudo do XX, os escritores sentiram a necessidade de buscar individualmente suas razões de escrever, e as razões de fazê-lo de determinada maneira. Decidiram estabelecer eles mesmos seus princípios e valores, e passaram a desenvolver, paralelamente às suas obras de criação, extensas obras de tipo teórico e crítico.

Leyla Perrone-Moisés 
De matriz surrealista, a atuação de Willer se dá, sobretudo, numa atitude que entrelaça sua produção com um modo de vida que, por sua vez, se desdobra nessa produção. O surrealismo, para além de um movimento de vanguarda, segundo Willer (2008a, p. 282), “[...] estaria voltado para a vida, o homem em sua totalidade e a transformação do mundo. A produção artística e literária foi o modo de expressar e realizar esse ímpeto transformador".

O poeta absorve, em sua prática, uma concepção da literatura como "sintoma" livre do cerceamento da razão e aberta à contemplação do caráter enigmático e mágico do universo. Nessa perspectiva é que se dá a tradução de obras importantes para os fundamentos do surrealismo, assim como sua atuação como difusor e promotor dessas diretrizes nas séries de eventos, acadêmicos e não acadêmicos, que envolvem, também, o âmbito das artes visuais, da música, do cinema e do teatro. Ao longo de sua atuação como poeta-crítico-teórico, são inúmeros seus artigos, palestras e conferências com os mais diversos interlocutores, fomentando o espaço para o debate do Surrealismo no Brasil.

Em 2013, num artigo intitulado Surrealismo no Brasil: crítica e criação literária (2013) ${ }^{8}$, Willer examina a situação da recepção do Surrealismo no Brasil por parte da crítica dominante:

\begin{abstract}
A propósito de correntes dominantes na crítica brasileira e sua convergência na rejeição do surrealismo, há uma crítica formalista, bem representada por Haroldo de Campos em Teoria da Poesia Concreta - Textos críticos e manifestos (Livraria Duas Cidades, 1975): "Evidentemente, a poesia concreta repudia o irracionalismo surrealista, o automatismo psíquico, o caos poético individualista e indisciplinado [...] O poema concreto não se nutre nos limbos amorfos do inconsciente, nem lhe é lícita essa patinação descontrolada por pistas oníricas de palavras ligadas ao subjetivismo arbitrário e inconsequente".
\end{abstract}

No mesmo artigo, cujo objetivo é trazer à luz, a despeito da recusa, a presença de importantes produções com a tônica surrealista, Willer prossegue:

\footnotetext{
Sérgio Lima, autor de A Aventura Surrealista (tomo 1 pelas editoras Vozes/ Unesp/ Unicamp, 1995; tomo 2 pela Edusp, 2010), em "Surrealismo no Brasil: mestiçagem e seqüestros", revê cronologias para demonstrar que houve, sim, atividade surrealista importante associada ao modernismo brasileiro, mas convertida em história subterrânea, não só no caso de Jorge de Lima e Murilo Mendes, dois grandes nomes de nossa poesia, mas em outros, como os autores que se reuniram ao redor da revista Verde de Cataguazes, Rosário Fusco, Guilhermino Cesar e o cineasta Humberto Mauro.
}

\footnotetext{
${ }^{8}$ Surrealismo no Brasil: crítica e criação literária (2013) é uma reedição com pequenas atualizações do que saiu recentemente em $A$ Ideia - revista de cultura libertária, n. 71-72, novembro de 2013, publicada em Évora, Portugal e, a seguir aqui, em Cronópios, http://cronopios.com.br/site/ensaios.asp?id=5788. Atualizações (surrealismo é um tema dinâmico) de artigos que havia publicado, no começo da década anterior, nas revistas Cult e Agulha.
} 
Como há dois modos de abordar o Surrealismo e ambos não são excludentes, explica Willer no mesmo artigo, já que um deles examina obras e o outro foca o autor e a atitude surrealista, a atenção voltada para um ou outro modo altera a história do Surrealismo no Brasil. E a partir dessa visão não excludente, ele apresenta uma série de poetas e prosadores brasileiros ligados ao Surrealismo não militante, ou seja, à rejeição da atitude formalista, à reafirmação do poder transformador da poesia, à riqueza imagética e em alguns casos de simbologia esotérica, à narrativa descontínua e onírica. O resultado, para além dos nomes já citados acima, é um conjunto significativo e diverso de autores brasileiros de várias gerações: Fernando Ferreira de Loanda, André Carneiro, Paulo Mendes Campos, Aníbal Machado, Campos de Carvalho, Sérgio Lima, Roberto Piva, Leila Ferraz, Raul Fiker, Péricles Prade, Floriano Martins, Manoel de Barros, Contador Borges, Sérgio Cohn, Augusto Guimarães Cavalcanti, José Geraldo Neres, Fabrício Clemente, Jeanine Will, Diogo Cardoso, Érica Zíngano, Renata Huber e Roberta Ferraz, entre outros.

A presença do Surrealismo no Brasil se deve menos à ausência de manifestações surrealistas e mais ao abafamento causado por um projeto político-cultural dominante que atingiu a crítica literária, a história da literatura brasileira e o mercado editorial. Entre os modernistas, o Surrealismo não foi bem aceito. Mário de Andrade, nome dos mais expressivos, advertiu: “[...] contra os 'perigos formidáveis da substituição da ordem intelectual pela ordem subconsciente"”. Chamava de "[...] erro perigosíssimo o modo como avulta na poesia a associação de imagens" (WILLER, 2019, s/p). Embora Oswald de Andrade, em seu manifesto e em seu livro, ambos denominados Pau-brasil, lançados em 1924, e com o lançamento, em 1928, da Revista Antropofagia e do "Manifesto Antropofágico", revele sua proximidade com a rebeldia dadaísta e surrealista, a partir de 1930, com a ideologia nacionalista e populista do Estado Federal, a literatura realista de vertente regionalista ganhou força enquanto o cosmopolitismo e o internacionalismo, predominantes entre 1922 e 1930, passaram a ser condenados. Em 1945, a crítica de Sérgio Milliet (1981) e de Antonio Candido (1992), em relação à primeira publicação de Rosário Fusco, $O$ agressor, ao adjetivá-lo de surrealista, imprimiu, no romance e em seu autor, um rótulo de desaprovação, uma vez que não corresponde às expectativas de um determinado projeto literário estabelecido pela crítica brasileira.

Nas últimas décadas, pesquisas acadêmicas sobre a produção literária ligada direta ou indiretamente ao Surrealismo, vêm, pouco a pouco, desobstruindo sua história subterrânea no Brasil. A atuação de Willer, assim como do poeta, artista plástico, tradutor, editor e ensaísta cearense Floriano Martins e a do poeta, artista plástico e ensaísta Sérgio Lima, na perspectiva da disseminação, pesquisa e reflexão sobre questões ligadas ao movimento, não deixa 
dúvida sobre a sua presença em território brasileiro. A falta não é de autores ligados ao Surrealismo, mas de um mercado editorial que fertilize o terreno bibliográfico ainda árido sobre tal questão. Não por acaso, alguns autores são também editores.

\title{
Fechando o círculo
}

Se o calendário de Willer é composto por "Dias circulares", assim também é sua criação poética, seja ela em verso ou em prosa, assim é seu trabalho como tradutor, crítico, ensaísta, sua produção e formação acadêmica, sua atuação como professor e como agente cultural. Desde sua estreia, com Apocalipse, contempla o mundo, os fatos, a partir da sua cama e, portanto, não se propõe a desvendar mistérios, nem a conhecer cartesianamente o mundo, mas a se deixar levar pelo seu obscuro encanto, por uma visão apocalíptica/visionária. Encontramos em toda sua ação, uma mesma energia, um mesmo movimento: a subversão do senso comum, a reintegração entre o sujeito e as coisas, entre o sujeito e o mundo a partir da magia das palavras. Portanto, afirma o próprio Willer:

\begin{abstract}
Não se trata apenas de estabelecer ligações entre poesia e vida: no limite, a poesia é vida, toda poesia autêntica nada mais é do que a explicitação de uma proposta vital. (WILLER, 2013, p. 67)

Interessa recuperar uma visão radical, e radicalmente crítica, do papel da arte e da criação na sociedade. Em uma época como a nossa, quando há um aparente eclipse de utopias, a rebelião romântica, individual, continuará a contribuir com a transformação do mundo. (WILLER, 2004b, p. 14)
\end{abstract}

Em "Surrealismo: poesia e poética", Willer, tomando de empréstimo as palavras de Octavio Paz, afirma que o Surrealismo não é uma poesia, mas uma visão de mundo:

\begin{abstract}
Essa visão do mundo abrange o modo como o surrealismo pensou a história da literatura; sua poética das correspondências, analogias e imagens; a visão do processo de criação, passando pela afirmação e discussão da escrita automática; a complexa relação entre poesia e vida, entre o simbólico e o real, incluindo o acaso objetivo. (WILLER, 2008a, p. 282)
\end{abstract}

Nesse texto, ele percorre cada uma das faces que integram o posicionamento do Surrealismo, articulando uma série de autores e artistas que o influenciaram, comentaram, fomentaram e integraram, esmiuçando as particularidades que, em vários aspectos (conceituais, processuais, formais) constituíram o que, para além de um movimento, como já foi dito, é um modo de estar no mundo.

\footnotetext{
9 Trocadilho com o poema "Dias circulares". In: Estranbas experiências e outros poemas. Rio de Janeiro: Lamparina, 2004, p. 114.
} 
Partindo das considerações de Perrone-Moisés, é possível compreender as várias atividades de Willer como componentes de um escopo necessário à vitalidade dos pressupostos surrealistas na atividade artística do país. Ainda jovem, tendo tido acesso àquele universo e compreendendo-o como motor e sentido de sua atividade como poeta e, do mesmo modo, como alguém situado num mundo em crise, seria inevitável a existência de reflexões e, sobretudo, de ações que visassem situar essa produção e, no fundo, o próprio homem, diante do mundo e do que a arte é capaz. Nesse sentido:

Escrevendo sobre as obras de seus predecessores e contemporâneos, os escritores buscam esclarecer sua própria atividade e orientar os rumos da escrita subsequente. A crítica dos escritores não visa simplesmente auxiliar e orientar o leitor, mas visa principalmente estabelecer critérios para nortear uma ação: sua própria escrita, presente e imediatamente futura. (PERRONE-MOISÉS, 1989, p. 11)

No empreendimento de uma vida ligada aos ideais surrealistas, vale também pensar na sua tese de doutorado, escrita aos 68 anos, como um momento em que reorganiza e reafirma sua trajetória de vida, marcada pela circularidade de seus múltiplos Eus (poeta, ensaísta, teórico crítico...), como nos apresenta o parecer de sua banca de doutorado:

A banca aprova a tese com distinção e louvor. Reconhece a leitura inovadora do trabalho de revisão da poesia moderna e da bibliografia especializada sobre o assunto. Releva a peculiaridade da sua abordagem que mescla erudição e competência crítica, no enfoque político da matéria poética ${ }^{10}$.

Olhar em retrospecto para a sua trajetória nos dá a possibilidade de compreender o sentido desse jogo profuso de Eus que se conectam de modo complexo, formulando a consistência de um pensamento que equivale àquilo que foi pensado. Afinal, "Somos assembleias de EUS e de INTELIGÊNCIAS” (WILLER, 2019, p. 113).

Embora a atuação de Willer se dê num contexto gerador das condições de possibilidade para um trabalho teórico crítico simultâneo ao da criação poética, esta também foi a maneira de atuar de André Breton e Octavio Paz, figuras imprescindíveis em sua formação. Todavia, “[...] a poesia é o último recurso e o mais radical” (AVES-BEZERRA, 2016, p. 48). E ele segue apagando os traços da fronteira entre arte e vida nos quais está enredado também como artista. É “[...] a voz surrealista [que] jamais se calará” (WILLER, 2016, p. 32):

\footnotetext{
${ }^{10}$ Parecer da banca examinadora da tese de doutorado "Um obscuro encanto: gnose, gnosticismo e a poesia moderna", composta por Benjamin Abdala Junior, orientador, Olgária Matos (FFLC-USP), Eliane Robert Moraes (PUC-SP), Maria Lúcia Dal Farra (UFS) e Moacir Amâncio (FFLCH-USP), disponível em: http://lattes.cnpq.br/7948027913325556
} 


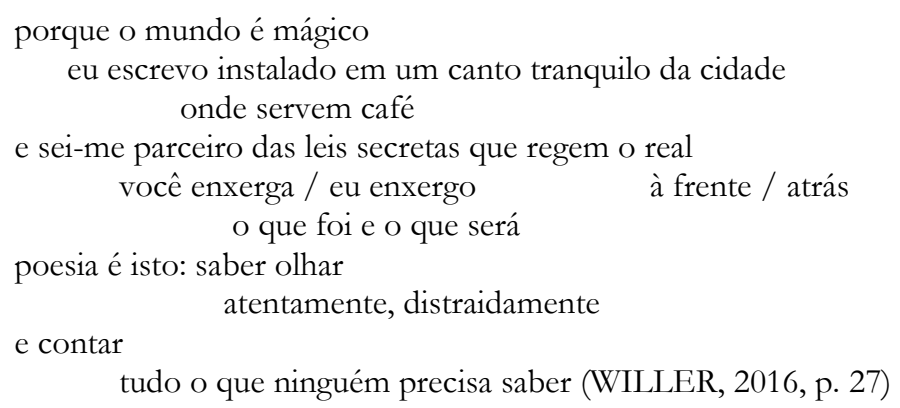

Sua poesia, afirma Henrique Duarte Neto (2018, p. 29), e acrescentamos, toda gama de suas atuações porque visam à poesia, “[...] representa um genuíno esforço por efetivar uma verdade, que pode ser entendida da seguinte forma: a realidade não está dada, devendo ser perscrutada e construída."

Willer completou, em dezembro de 2020, 80 anos. A imagem do apfelstrudel é a síntese do próprio poeta: pai judeu austríaco + mãe alemã cristã $=$ claudiostrudel ou willerstrudel, 80 camadas da mais fina massa folheada de múltiplos Eus e recheadas de doces, estranhos e maravilhosos encontros - com pessoas, pensamentos, outros poetas, outras artes, com muitos e "modernos amores". Um apfelstrudel generoso e muito singular, herdeiro da rebelião romântica, e que temos o privilégio de saborear.

\title{
APFELSTRUDEL, 80 LAYERS OF THE FINEST PLATED PASS OF MULTIPLE SELVES: A TRIBUTE TO CLAUDIO WILLER
}

\begin{abstract}
This essay is a tribute to the São Paulo's poet, essayist and translator Claudio Willer who, in December 2020, completed 80 years. Through a dialogue among his prose texts, some poems and critical fortune, an examination of his trajectory, which began in the mid-1960s, will be carried out. In a surrealistic matrix, his procedure takes place, above all, in an attitude that intertwines his production with a way of life that, in turn, unfolds in this production. In his practice, the poet absorbs a conception of literature free from the restriction of reason and open to contemplation of the enigmatic and magical character of the universe. In this perspective, he translated works by important foundation authors of Surrealism and Beat literature. Based on the considerations of Leila Perrone-Moisés, it is possible to understand the multiple actions of Willer - his profuse game of selves, poet, translator and theoretical critic, with the most diverse interlocutors - as components of a scope necessary for the vitality of the surrealistic assumptions in the brazilian artistic and literary activity. The intersection of his actions also signals the intertextuality very tessiture of his poetry - his most radical resource. After all, an anti aristotelian inside out, the poetic word is, for Willer, a magical agent that produces reality.
\end{abstract}

KEYWORDS: Claudio Willer; Poetry; Surrealism in Brazil; Critical poetic / theoretical trajectory

\section{REFERÊNCIAS}

AVES-BEZERRA, Wilson. Posfácio. Claudio Willer lança A verdadeira história do século 20. In: WILLER, Claudio. A verdadeira bistória do século 20. São Paulo: Córrego, 2016. p. 47-48.

ANDRADE, Oswald. Obras completas. Rio de Janeiro: Civilização Brasileira, 1971. 
BIRO, Adam; PASSERON, René (direct.). Dictionnaire général du Surréalisme et de ses environs. Paris: Presses Universitaires de France, 1985.

BRETON, André. Manifesto do Surrealismo. In: Manifestos do Surrealismo. Trad. Sergio Pachá. Rio de Janeiro: Nau Editora, 2001. p. 13-64.

CAMPOS, Augusto de; PIGNATARI, Décio; CAMPOS, Haroldo de. Plano-piloto para poesia concreta. In: AMARAL, Aracy (coord.). Projeto construtivo brasileiro na arte (1950-1962). Rio de Janeiro: Museu de Arte Moderna; São Paulo: Pinacoteca do estado, 1977. p. 78-79.

CANDIDO, Antonio. Surrealismo no Brasil. In: Brigada ligeira e outros escritos. São Paulo: Ed. UNESP, 1992. p. 103-107.

CHENIEUX-GENDRON, Jacqueline. O surrealismo. Trad. Mário Laranjeira. São Paulo: Martins Fontes, 1992.

CLEMENTE, Fabrício Carlos. Estilhaços de visões: poesia e poética em Roberto Piva e Claudio Willer. 2012. 122 f. (Mestrado em Teoria Literária e Literatura Comparada) - Faculdade de Filosofia, Letras e Ciências Humanas, Universidade de São Paulo, São Paulo, 2012.

COELHO, Nelly Novaes. Carlos Nejar e a "geração de 60”. São Paulo: Saraiva, 1971.

DUARTE NETO, Henrique. Claudio Willer: o universo onírico e surrealista em terras brasileiras. São Paulo: Córrego, 2018.

LYRA, Pedro. Sincretismo: a poesia da geração 60: introdução e antologia. Rio de Janeiro: Topboocks, 1995.

MARTINS, Floriano. A transgressão inatingivel: uma leitura dos manifestos de Claudio Willer. In: WILLER, Claudio. Manifestos 1964-2010. Rio de janeiro: Azougue, 2013. p. 183-190.

MILIIET, Sérgio. Diário crítico de Sérgio Milliet (1940-1943). Vol. I., 2a ed., São Paulo: Livraria Martins/Edusp, 1981.

NEJAR, Carlos. História da literatura brasileira: da carte de Caminha aos contemporâneos. São Paulo: Leya, 2011.

PAZ, Octavio. O arco e a lira. Trad. Ari Roitman e Paulina Wacht. São Paulo: Cosac Naïfy, 2012.

PERRONE-MOISÉS, Leyla. Altas literaturas. São Paulo: Companhia das Letras, 1989.

SCHOLEM, Gershom. O nome de Deus, a teoria da linguagem e outros estudos de cabala mística: Judaica II. Trad. Ruth Joanna Solon e Jacó Guinsburg. São Paulo: Perspectiva, 1999.

SÜSSEKIND, Flora. Rodapés, tratados e ensaios - a formação da crítica brasileira moderna. In: . Papéis colados. Rio de Janeiro: Editora da UFRJ, 1993. p. 13-33.

WILLER, Claudio. Surrealismo no Brasil: crítica e criação literária. Disponível em: http://qorpus.paginas.ufsc.br/como-e/edicao-n-013/surrealismo-no-brasil-critica-e-criacao-literaria-claudio-willer/. Acesso em: 21 fev. 2021. Estranhas experiências e outros poemas. Rio de Janeiro: Lamparina, 2004a. Volta. São Paulo: Iluminuras, 2004b. 
WILLER, Claudio. Um obscuro encanto: gnose, gnosticismo e a poesia moderna. 2007. 385 f. Tese (Doutorado em Estudos Comparados de Literaturas de Língua Portuguesa) - Faculdade de Filosofia, Letras e Ciências Humanas, Universidade de São Paulo, São Paulo, 2007.

Surrealismo: poesia e poética In: GUINSBURG, J.; LEIRNER, S. O surrealismo. São Paulo: Perspectiva, 2008. p. 281-322.

. Manifestos 1964-2010. Rio de janeiro: Azougue, 2013.

- A verdadeira história do século 20. São Paulo: Córrego, 2016.

- Dias ácidos, noites lisérgicas. São Paulo: Córrego, 2019.

. Dias circulares. Revista Cult, disponível em: https://revistacult.uol.com.br/home/ dias-circulares/ Acesso em 12 abr. 2021.

Diálogo com o poeta e tradutor Cláudio Willer. Entrevista concedida a Edson Cruz Stream em direto de 24/04/2021. In: Confraria da Palavra. Disponível em: https:// www.youtube.com/watch?v $={ }_{w X X} 4 \mathrm{q} 8 \mathrm{IAGmI}$

Recebido em: 30/04/2021.

Aprovado em: 30/06/2021. 